\title{
Level of Knowledge on Reproductive Health and Use of Family Planning among two Groups of Low-Income Families
}

\author{
Emolyn M. Iringan \\ Josephine D. Lorica \\ St. Paul University Philippines \\ Mabini, Street, Tuguegarao City \\ Philippines 3500
}

\begin{abstract}
This cross-sectional, descriptive-comparative study explored on the level of knowledge on Reproductive Health (RH) and use of Family Planning (FP) methods among two groups of low-income couples in the northeastern region of the Philippines. Study participants were $2924 P s$ and 188 non-4Ps. The data obtained through validated questionnaires and interviews were analyzed using the frequency and percentage, scales and weighted mean, $t$-test, chi-square and thematic analysis. Results show couples' high level of knowledge on artificial and traditional methods and a moderate level of knowledge on Scientific Modern NFP methods. No variation exists on the knowledge and use of family planning methods between the two groups except for their knowledge on Basal Body Temperature, Standard Days Method, Calendar method and their use of Depo-Provera for which 4Ps' rating is higher than non-4Ps. The family planning programs contributed to the high level of knowledge and extent of use of the family planning methods among couples.
\end{abstract}

Keywords: Reproductive Health Knowledge, Use of Family Planning, Low-Income families

\section{Introduction}

Population, poverty and economic development have shown causality in recent decades. High population growth, particularly in developing countries, impedes economic progress, depriving those societies of funds for investment and opportunities for an improved standard of living. Increasing fertility trends further exacerbate all aspects of poverty. Hence, government leaders plan for effective strategies for poverty reduction and for population policy formulation. In the Philippines, the Department of Health and the Commission on Population launched and implemented the Responsible Parenting Movement (RPM) in 2007. RPM is one aggressive move and systematic strategy to promote responsible parenting and natural family planning. It is a grassroots campaign to bring the program closer to its target beneficiaries. To activate the group of parents who are involved in the program, classes in responsible parenting are held in the barangays. Each class is composed of 10 married couples of childbearing age who want to practice birth spacing through natural family planning methods (NFP). These couples should be willing to recruit other couples to become members of the RPM. RPM's 8-hour session covers topics such as Responsible Parenting, Fertility Awareness, and Natural Family Planning. This program empowers Filipino families to consider responsible parenting as a way of life and a means for the attainment of sustainable human development. Reproductive Health is "a condition in which the reproductive health functions and processes are accomplished in a state of complete mental and social well-being." (Department of Health, n.d.). Reproductive health is commonly associated with women's health and rarely involving husbands in their studies. But concerning the abovementioned laudable project in 2012, the Commission on Population was tasked by the Aquino Administration to sustain the gains of the RPM classes by giving priority to Pantawid Pamilya Pilipino Program (4Ps) couple recipients as participants. In this project, POPCOM and the Department of Social Welfare and Development (DSWD) developed the Family Development Session (FDS) Sub-module 2.2 on Responsible Parenthood/Family Planning (RP/FP). The said module is an additional module to the existing FDS used by the DSWD for their 4Ps couple recipients. The Pantawid Pamilyang Pilipino Program (4Ps) is the Philippine government intervention that provides cash grants with certain conditions to the poorest families in the country "to improve the health, nutrition and the education of children aged 0-18" (Official Gazette, 2019). Dungog -Cuizon, and Cuizon (2016) presented that the 4Ps have dual objectives "poverty alleviation and investment in human capital." The cash grants are provided with the conditions provided for by the program and among the conditions is the attendance of the couples to the regular FDS sessions. As Nallari \& Griffith (2011) concluded, "the provision of basic health care is critical for economic progress." 
Thus, considering the program provided by the government, the study aims to determine the level of knowledge and use of family planning among two groups of low-income families in the Northeastern Region in the Philippines and their characteristics by looking at the socio-demographic characteristics and also the wives' reproductive profile. To determine the differences in the knowledge level on Reproductive health, use of family planning methods and other characteristics, the participants were divided into 4Ps and non 4Ps. The paper further aims to propose interventions to improve the couples' knowledge and use of FP methods.

\section{Statement of the Problem}

This study determined the characteristics, the level of knowledge on Reproductive Health and Use of Family Planning methods among the two groups of low-income couples' in the northeastern region of the Philippines.

More specifically, the study aimed to answer the following problems:

1. What are the characteristics of the two groups of participants in terms of

1.1. the socio-demographic profile of the couples?

1.2. Reproductive health profile of the wives?

2. What is the couples' level of knowledge on reproductive health and use of the family planning methods?

3. Is there a significant difference in the level of knowledge and use of the family planning methods between the two groups of couples?

4. What health intervention can be proposed to improve couples' reproductive health knowledge and status?

\section{Methods}

\subsection{Research Design}

This cross-sectional study utilized the quantitative research approach. Specifically, it utilized the descriptivecomparative research design. This design is apt as it characterized the couples in terms of their socio-demographic and reproductive health profile and status. The comparison between the two groups of couples along the stated variables utilized the comparative design.

\subsection{Participants of the Study}

The participants of the study were the 4Ps and non-4Ps couples in selected municipalities of the four provinces in Region 02, namely, Cagayan, Isabela, Nueva Vizcaya, and Quirino. These couples were attendees to either the Family Development Session Sub-Module 2 jointly conducted by the Commission on Population (POPCOM) Office and DSWD or the sessions under the Responsible Parenting Movement conducted by POPCOM. Municipalities were purposively sampled to ensure the representativeness of the 4Ps and non-4Ps participants. Of the 35,377 recorded couples, 21,112 are 4Ps while 14,265 are non-4Ps beneficiaries. The study considered 480 pparticipants which included 292 recruited 4Ps and 188 recruited non-4Ps. The participants per municipality were selected from each covered barangay to be represented. The wife, the husband or both were considered as one participant.

\subsection{Instrumentation}

The survey tool used to collect data was constructed based on existing tools and literature on reproductive health. This contained a checklist on the socio-demographic profile (i.e. (i.e. Municipality class, combined monthly income, ages, educational attainment, occupation, religion, ethnicity, and number of children), wives' reproductive health profile (i.e. wives' age at marriage and menarche, number of pregnancies, spacing between pregnancies, and delivery profile), and couples' level of knowledge and use of the family planning methods. The tool was validated by five health experts to ensure its appropriateness, completeness, and accuracy,

\subsection{Data Gathering Procedure}

The researchers obtained the list of 4Ps and non-4Ps who participated in the Reproductive Health (RH) and Family Planning (FP) awareness sessions from the Commission on Population Office and the DSWD Office. Before the data gathering phase, the researchers sought endorsement from the head of the Commission on Population, the Department of Social Welfare and Development, and the Department of Health. Permission from the provincial as well as the municipality administrators of the respondent municipalities was likewise obtained. Upon approval, the researchers determined the location of the probable participants and coordinated with the municipal population officer, the 4Ps municipal links and concerned barangay council to ensure systematic data gathering. There were trained data enumerators in administering the questionnaires to ensure valid and reliable results. Informed consent was obtained from each of the participants before the administration of the questionnaires. The enumerators guided the particpants as they filled out the questionnaires. 


\subsection{Data Analysis}

Descriptive and inferential statistics were used to treat the data. More specifically, the frequency and percentage were used to treat the participants' socio-demographic and reproductive health profile. Scaled responses were treated using the weighted mean with a corresponding scale of interpretation. The t-test for independent samples and Chi-square test were employed for the tests of differences. The qualitative data from the interviews were analyzed in themes.

\section{Results and Discussion}

\subsection{Couples' Socio-demographic profile}

Municipality Class. Majority of the 4Ps [58.22\%] and non-4Ps [62.23\%] reside in first-class municipalities. First class municipalities in the Philippines are those falling within the highest bracket of annual revenues.

Monthly Income. Majority of the 4Ps [71.23\%] and non-4Ps [74.47\%] couples have monthly income below P5,000.00. Also, $25.34 \%$ of the 4 Ps couples and $21.81 \%$ of the non-4Ps couples have a total monthly income ranging from P5,0009,999. The data indicate that couples have limited financial resources; thus, they are expected to limit the number of their children to sustain the growing needs of their families.

Age. Most of the 4Ps and non-4Ps wives are within the age range of 30 to 44 while most of the husbands in both groups have ages ranging from 35 to 44 . The mean ages of 4Ps and non-4Ps wives are 35.98 and 36.24, respectively, while the mean ages of husbands are 39.23 and 39.71, respectively. The overall mean ages of wives and husbands are 36.11 and 39.47 , respectively. The data show that wives are younger than their husbands.

Educational Attainment. About 50\% of the 4Ps and non-4Ps wives either reached or finished high school level. Almost the same proportion (more or less 20\%) of the 4Ps husbands reached or graduated from elementary or high school level. For the non-4Ps husbands, $24.47 \%$ of them reached high school level, approximately $22 \%$ were high school graduates, and $19.15 \%$ reached elementary level. The biggest cohorts of couples are high school undergraduates and high school graduates.

Employment. Majority or $85.96 \%$ 4Ps wives and $78.19 \%$ non-4Ps wives are unemployed. Most [55.48\%] of the 4Ps husbands are self-employed while $29.45 \%$ of them are employed on a daily wage basis. The highest percentage of the non-4Ps husbands are employed on a daily wage basis, followed by those who are self-employed and those employed on a commission basis as reflected by the percentages of $37.23 \%, 27.66 \%$, and $25.53 \%$, respectively. The majority [82.92\%] of the wife-respondents are unemployed since they are housewives. Most [44.58\%] of the husbandrespondents are self-employed as farmers, fishermen, and businessmen while $32.50 \%$ of them are employed on a daily wage basis as laborers (hired on a commission basis) or drivers (company drivers).

Religion. Majority of the couples in both groups are Roman Catholics as evidenced by the specific and overall percentages ranging from 71\% to 79\%. This finding is supported by the 2019 Philippine Population Review which disclosed that Roman Catholics make up the majority (81\%) of the country's population.

Ethnicity. Among the top three common ethnicities are the Ilocanos, Tagalogs, and Ibanags. Majority of the couples in both groups belong to the Ilocano ethnic group. This information supports the fact that Ibanag, Itawes and Ilocano and Malaueg are the most commonly spoken dialects in Cagayan and that "migration made Ilocano the dominant language spoken in the province." (Suyu, 2015)

Number of Children. The two groups of couples show that most of the couples have 3-4 children. This result is supported by the percentages of $44.86 \%$ and $39.89 \%$ for the 4Ps and non-4Ps groups, respectively. The total frequencies/percentages show that $42.92 \%$ of couples have 3-4 children followed by those with 1-2 children. The mean number of children per family is 3.82. This figure is closed to 3.3, which is the obtained average number of children per family, with 2.8 in urban areas and 3.8 in rural areas as reported by the Philippine National Demographic and Health Survey in 2008 (National Statistics Office [Philippines] and ICF Macro,2009).

\subsection{Wife's Reproductive Health Profile}

Wives' age at marriage. Most of the wives got married at age range 18-20. The mean ages at marriage of 4Ps and non4Ps wives are 20.54 and 20.88 , respectively. 83 or $17.29 \%$ of the wives married at an early age since they did not meet the legal age of 18. Most or 42.29\% of the wives got married with parental consent (ages 18-20) while 194 or $40.42 \%$ of them married where parental consent is not required. According to Beal (2014), "women are at the peak of their fertility in their $20 \mathrm{~s}$ "; thus, the overall mean age of wives at marriage which is 20.68 indicates that majority of them got married at an age where the fertility rate is at its peak.

Age at Menarche. Most of the 4Ps wives experienced menarche at ages 10-13 years old [47.60\%] and 14-16 years old [48.29\%]. For the non-4Ps wives, majority [56.91\%] had their menarche at 10-13 years old, and $40.43 \%$ had it at age 14-16. Menarche occurs between the ages 10 to 16 years in most girls in developed countries (Rees, 1995). As a whole, the wives had their menarche at ages 10-16 which is considered within the normal menarche age. 
It can be noted further that one respondent experienced early menarche at age nine while about $3.33 \%$ of the respondents had late menarche at age 17.

Number of Pregnancies. Most of the 4Ps [44.52\%] and the non-4Ps [38.30\%] wives had 3-4 pregnancies. In general, $42.08 \%$ of the wives had 3-4 pregnancies, followed by those with 1-2 or 5-6 pregnancies. The mean number of pregnancies among wives is 4.02. This result corroborates the findings of the 2013 National Demographic and Health Survey that couples are not able to realize their desired fertility of 2 children on the average.

Gaps Between Pregnancies. In terms of years, the least gap between pregnancies is 0 (less than a year) and the most common gap between pregnancies among 4Ps, and non-4Ps respondents are 1 or 2 years. The Department of Health advocates 3-5 years of birth spacing. This recommended birth spacing is to allow the "mother to recuperate from pregnancy, labor, and lactation" [and to]"replenish her nutritional stores like iron, calcium, and vitamins". Furthermore, this is also to ensure that the "physical, psychological, intellectual and emotional needs of the child are well-taken cared of" (Dar, 2011). The results further reveal that about $41 \%$ of the wives did not comply with the prescribed pregnancy gap, which can pose possible health risks for both mothers and babies.

Child Delivery. Most or $23.75 \%$ of the wives had exactly three child deliveries, followed by those with 2 . An isolated case of 1 wife with 13 pregnancies had only two successful child deliveries. The data also reveal that there are cases of failed deliveries among women. Further, the majority or $88.13 \%$ of the wives had a complete number of child deliveries based on their number of pregnancies. Moreover, 46 or about $10 \%$ of them had one miscarriage, and 9 or about $2 \%$ had two miscarriages, and isolated cases of 3 and 11 miscarriages. Based on the interviews conducted, such abortion cases were not induced; instead, they were spontaneous. The majority [93.96\%] of the wives had a complete number of full-term deliveries. There were 29 cases [6.04\%] of wives experienced pre-term deliveries, 469 [97.71\% ] wives experienced normal delivery and 11 or 2.29 never experienced normal delivery. There were 55 [11.46\%] wives with Caesarian deliveries while 425 or $88.14 \%$ did not have any experience of Caesarian delivery. Majority or $88.14 \%$ of the wives have normal delivery for all their children, 11 or $2.29 \%$ delivered all their children through Caesarian and 44 or $9.17 \%$ had normal and Caesarian deliveries. The majority [95.21] of the 4Ps and non-4Ps respondents utilize the family planning methods while a few of them neither use any of the traditional, artificial nor scientific NFP methods. The obtained percentage of FP users is significantly higher than the recorded rate $(50.70 \%)$ on contraceptive prevalence among women ages 15-49 (World Bank, 2008). The increase in the number of FP users is attributed to their exposure to family planning programs initiated by the government.

\subsection{Couples' level of knowledge and use of the family planning methods}

Knowledge of family planning. Both 4Ps and non-4Ps couples' level of knowledge on artificial and traditional methods is generally high except for Vasectomy and Calendar/Rhythm methods for which they have 'moderate' knowledge level. Awareness sessions on this cluster of FP methods were conducted since the late 70s when the Population Act of 1971 was enforced. The long tradition of artificial and traditional FP method used by couples for more than four decades may have contributed significantly to their high level of understanding of the Family Planning methods. It can be further deduced that the knowledge of both groups of respondents on the natural scientific family planning methods ranges from low to moderate levels. More specifically, among the scientific NFP methods, the 'two-day method' is rated low.

Based on the interview, respondents have not fully understood the scientific methods despite their attendance to the RPM and FDS sessions. This is traced to the intricate processes involved and the lack of follow-up or enhancement sessions in the local health units regarding the utilization of the modern natural FP methods.

Family Planning Methods Used. The 4Ps wives used pills [69.86\%] and Depo Provera [69.86\%] while 22.60\% of the 4Ps husbands used the withdrawal method. For the non-4Ps couples, $73.94 \%$ of the wives are pill users while $27.66 \%$ of them use injectable Depo Provera. Also, the withdrawal method is utilized by $23.94 \%$ of 4Ps husbands. In general, the pill is the most commonly used Family Planning method by the majority [72.29\%] of both groups of wives. Also, $36.25 \%$ used injectable (Depo Provera) and $25.21 \%$ used the withdrawal method. The least utilized family planning methods are the 'two-day method' and 'vasectomy.' However, the DOH has not advocated the use of withdrawal and calendar methods because of their low level of effectiveness (Department of Health, n.d). Based on the interviews conducted, despite their claims on the side effects of pills and injectable (Depo Provera), the wives have a high preference for these artificial FP methods as they consider them effective, convenient and easy to use. The free supply of birth control pills made available in the local health centers, the variety of birth control pills sold in drugstores provided options for women to try out those with minimal side effects. With the diverse tasks of women, they also opted to use injectable despite its daunting side effect as one shot lasts for six (6) months. The participants claim that vasectomy is detrimental to their husbands' health since they do physical labor for the family. Thus, resulting in a low preference for vasectomy as a family planning method. 
Concerning the scientific natural family planning methods used, only about $0.05 \%$ to $2 \%$ of the women use either the Basal Body Temperature Method, Sympto-Thermal Method, Billings Ovulation/Cervical Mucus Method, Standard Days Method, or Two-day Method while about 9\% practice Lactational Amenorrhea Method. The intricacies of the scientific NFP methods hinder the respondents from using them. The limited use of natural scientific family planning methods may also be attributed to the midwives' insinuation on the respondents to use artificial FP methods. Although RPM, as well as the FDS Sub-module 2.2, provide adequate information about these methods, couples have not fully assimilated the procedures for their successful use. The lack of the necessary gadgets (i.e., thermometer, beads) as well as follow-up or deepening sessions at the local level led the respondents to resort to more natural and more convenient family planning methods.

Some family planning methods used. Among the six scientific NFP methods, the majority [88.33\%] of the respondents did not try any of these methods. Only about $10 \%$ tried one method, and about $2 \%$ tried more than two modes. Also, of the six artificial methods, $46.67 \%$ of the respondents tried 1 of the methods, $33.96 \%$ tried two, and only $10.83 \%$ never tried any of the methods. For the two traditional methods, the majority [71.67\%] never tried, $22.50 \%$ tried one method, and only about $6 \%$ tried two methods (calendar method and withdrawal method). Among the noted practices on the use of the family planning methods were method switching (274 or $57.08 \%$ ), alternate use of pills and depoprovera (46 or $9.58 \%$ ), trying different brands of oral pills ( 72 or 15\%), use of permanent FP methods such as ligation and vasectomy (70 or $14.59 \%$ ) contraceptive discontinuation or abandoned use of FP methods (32 or $6.67 \%$ ), and taking oral pills when husband arrives (13 or 3.33\%). The respondents tried to use FP methods; however, they decided to discontinue due to husband's disapproval, health conditions, fear of side effects, and contraceptive failure. Also, some of those who used more than two methods have switched to other FP methods to determine which of them is more convenient to use and with fewer side-effects.

\subsection{Comparison of the Level of Knowledge and Family Planning Methods Used Among 4Ps and non-4Ps}

Comparison of Level of Knowledge. There are no significant variations on the 4Ps and non-4Ps couples' knowledge on the different family planning methods except for their knowledge on Basal Body Temperature Method, Standard Days method, and Calendar Methods as evidenced by the probability values of 0.045, 0.04 and 0.04, respectively. The obtained means reveal that 4Ps couples' knowledge is significantly higher than those of the non-4Ps concerning the FP as mentioned earlier methods. Based on the interview, the 4Ps regularly visit the Local Health Center as a requirement for all recipients of the program, thus, giving them more opportunities to obtain information about the family planning methods.

\section{Comparison of Utilization of the scientific methods of family planning}

The 4Ps and non-4Ps couples do not differ significantly in terms of their utilization of the various family planning methods except for Depo Provera. The obtained percentages reveal that there is a higher proportion of 4Ps than non4Ps using Depo Provera. The data underscore that the 4Ps and non-4Ps couples manifest the same preferences as regards the utilization of family planning methods. This result reflects the equitable access to information, health support, and services of the government in its family planning promotion initiatives.

\subsection{The proposed reproductive health intervention program}

The intervention program provides a frame of reference that can be adopted or be enriched by the Commission on Population in its ceaseless quest for appropriate strategies that will help promote its advocacies on reproductive health and responsible parenthood. The program generally aims to implement activities that help support favorable family planning practices and improve reproductive health status among couples. The program seeks explicitly to intensify mobilization of barangay health workers and significant others in the dissemination of family planning services, intensify/encourage the involvement of other stakeholders in the program education, and improve the accessibility of RH services.

\section{Conclusion}

Abortions, pre-term deliveries, and short birth gaps pose risks for the couples' reproductive health. Various improvements in the family planning programs introduced by the government through the Commission on Population (PopCom), Department of Health (DOH) and Department of Social Welfare and Development (DSWD has contributed significantly on the high extent of utilization of the family planning methods among couples, although their campaign for the use of natural scientific methods are not highly patronized.

\section{Recommendations}

In light of the findings and the conclusion, the following are recommended: 
1. The government must consider expansion on women's access to information about the scientific natural family method and improved accessibility of the needed gadgets (thermometer, fertility beads) in the local health centers in intensifying its campaign strategy on the use of safe birth control methods.

2. Conduct of seminars for couples on fertility awareness, family planning methods, and responsible parenthood must be sustained and must also include the following topics:

2.1 efficacy of the different birth control methods and their ascribed side-effects

2.2 the economic impact of the reduced number of children

2.3 advantages of proper birth spacing and the risks for short pregnancy gaps on both mother and child

2.4 probable complications of simple sex-related symptoms such as UTI, menstrual irregularities and abnormalities

2.5 causes, symptoms, and treatment for abortions, sexually transmitted diseases, cancers (breast, cervical, uterus, prostate, and the like)and infertility.

3. To sustain the quality services of the health centers along reproductive health, and to ensure adequacy and availability of birth control gadgets/materials to address family planning needs in their respective service domain, government financial support is necessary.

4. Couples also tend to seek advice from Barangay Health Workers and elders (mothers, older sisters); hence, such health support groups should undergo intensive training to enhance and update their knowledge/skills on human fertility, use of birth control methods and handling of problems on reproductive health.

5. Case analysis on abortion and pre-term deliveries may be done to generate useful information to lessen recurrence of cases and probable complications.

6. The Commission on Population (PopCom) and Department of Health (DOH)would introduce measures to improve couples' knowledge and use of scientific family planning methods.

7. Schools must share in the government's campaign on reproductive health and responsible parenthood by integrating lessons on fertility awareness, family planning and responsible parenthood in the areas where they are most relevant.

8. Since the study only dealt with 4Ps and non-4Ps, further research on larger samples should include those coming from different income and professional groups. The qualitative approach is recommended for in-depth analysis of the couple's practices on contraceptive use.

Table 1. Participants of the study

\begin{tabular}{|c|c|c|c|c|c|c|}
\hline \multirow[t]{2}{*}{ Province } & \multicolumn{2}{|l|}{ 4Ps } & \multicolumn{2}{|c|}{ Non-4Ps } & \multicolumn{2}{|c|}{ Total } \\
\hline & $\mathrm{F}$ & $(\%)$ & $\mathrm{F}$ & (\%) & $\mathrm{F}$ & $(\%)$ \\
\hline Cagayan & 106 & 36.30 & 80 & 42.55 & 186 & 38.75 \\
\hline Isabela & 107 & 36.64 & 68 & 36.17 & 175 & 36.46 \\
\hline Nueva Vizcaya & 53 & 18.15 & 16 & 8.51 & 69 & 14.38 \\
\hline Quirino & 26 & 8.90 & 24 & 12.77 & 50 & 10.42 \\
\hline Total & 292 & 100.00 & 188 & 100.00 & 480 & 100.00 \\
\hline
\end{tabular}

Table 2. Couple's municipality class, age at marriage, and monthly income

\begin{tabular}{|c|c|c|c|c|c|c|c|}
\hline \multicolumn{2}{|l|}{ Profile } & \multicolumn{2}{|l|}{ 4Ps } & \multicolumn{2}{|c|}{ Non-4Ps } & \multicolumn{2}{|c|}{ Total } \\
\hline & & $\mathbf{F}$ & $(\%)$ & $\mathbf{F}$ & $(\%)$ & $\mathbf{F}$ & $(\%)$ \\
\hline \multirow[t]{4}{*}{ Municipality class } & First Class & 170 & 58.22 & 117 & 62.23 & 287 & 59.79 \\
\hline & Second Class & 34 & 11.64 & 5 & 2.66 & 39 & 8.13 \\
\hline & Third Class & 46 & 15.75 & 30 & 15.96 & 76 & 15.83 \\
\hline & Fourth Class & 42 & 14.38 & 36 & 19.15 & 78 & 16.25 \\
\hline \multirow{5}{*}{$\begin{array}{l}\text { Couples' } \quad \text { Monthly } \\
\text { Income }\end{array}$} & Below P5,000 & 208 & 71.23 & 140 & 74.47 & 348 & 72.50 \\
\hline & P5,000 - P9,999 & 74 & 25.34 & 41 & 21.81 & 115 & 23.96 \\
\hline & P10,000 - P14,999 & 6 & 2.05 & 4 & 2.13 & 10 & 2.08 \\
\hline & P15,000 - P19,999 & 3 & 1.03 & & 0.00 & 3 & 0.63 \\
\hline & More than $\mathrm{P} 20,000$ & 1 & 0.34 & 3 & 1.60 & 4 & 0.83 \\
\hline
\end{tabular}


Table 3. Couples' Ages

\begin{tabular}{|c|c|c|c|c|c|c|c|c|c|c|c|c|}
\hline \multirow{3}{*}{$\begin{array}{l}\text { Age } \\
\text { Range }\end{array}$} & \multicolumn{4}{|c|}{ 4Ps } & \multicolumn{4}{|c|}{ Non-4PS } & \multicolumn{4}{|c|}{ Total } \\
\hline & \multicolumn{2}{|c|}{$\begin{array}{l}\text { Wife } \\
x=35.98\end{array}$} & \multicolumn{2}{|c|}{$\begin{array}{l}\text { Husband } \\
x=39.23\end{array}$} & \multicolumn{2}{|c|}{$\begin{array}{l}\text { Wife } \\
36.24\end{array}$} & \multicolumn{2}{|c|}{$\begin{array}{l}\text { Husband } \\
x=39.71\end{array}$} & \multicolumn{2}{|c|}{$\begin{array}{l}\text { Wife } \\
x=36.11\end{array}$} & \multicolumn{2}{|c|}{$\begin{array}{l}\text { Husband } \\
x=39.47\end{array}$} \\
\hline & $\mathrm{F}$ & $\%$ & $F$ & $\%$ & $\mathrm{~F}$ & $\%$ & $\mathrm{~F}$ & $\%$ & $\mathrm{~F}$ & $\%$ & $\mathrm{~F}$ & $\%$ \\
\hline$<19$ & & & & & 1 & 0.53 & & & 1 & 0.21 & & \\
\hline $20-24$ & 11 & 3.77 & 3 & 1.03 & 13 & 6.91 & 6 & 3.19 & 24 & 5.00 & 9 & 1.88 \\
\hline $25-29$ & 33 & 11.30 & 19 & 6.51 & 26 & 13.83 & 19 & 10.11 & 59 & 12.29 & 38 & 7.92 \\
\hline $30-34$ & 71 & 24.32 & 47 & 16.10 & 34 & 18.09 & 32 & 17.02 & 105 & 21.88 & 79 & 16.46 \\
\hline $35-39$ & 75 & 25.68 & 76 & 26.03 & 43 & 22.87 & 39 & 20.74 & 118 & 24.58 & 115 & 23.96 \\
\hline $40-44$ & 76 & 26.03 & 70 & 23.97 & 55 & 29.26 & 47 & 25.00 & 131 & 27.29 & 117 & 24.38 \\
\hline $45-49$ & 26 & 8.90 & 50 & 17.12 & 16 & 8.51 & 29 & 15.43 & 42 & 8.75 & 79 & 16.46 \\
\hline$>50$ & & & 27 & 9.25 & & & 16 & 8.51 & & 0.21 & 43 & 8.96 \\
\hline
\end{tabular}

Table 4. Couples' educational attainment

\begin{tabular}{|c|c|c|c|c|c|c|c|c|c|c|c|c|}
\hline \multirow[t]{3}{*}{ Educational Level } & \multicolumn{4}{|c|}{ 4Ps } & \multicolumn{4}{|c|}{ Non-4PS } & \multicolumn{4}{|c|}{ Total } \\
\hline & \multicolumn{2}{|c|}{ Wife } & \multicolumn{2}{|c|}{ Husband } & \multicolumn{2}{|c|}{ Wife } & \multicolumn{2}{|c|}{ Husband } & \multicolumn{2}{|c|}{ Wife } & \multicolumn{2}{|c|}{ Husband } \\
\hline & $\mathbf{F}$ & $(\%)$ & $\mathbf{F}$ & $(\%)$ & $\mathbf{F}$ & $(\%)$ & $\mathbf{F}$ & $(\%)$ & $\mathbf{F}$ & $(\%)$ & $\mathbf{F}$ & $(\%)$ \\
\hline Elementary Level & 35 & 11.99 & 57 & 19.52 & 21 & 11.17 & 36 & 19.15 & 56 & 11.67 & 93 & 19.38 \\
\hline Elementary Graduate & 39 & 13.36 & 56 & 19.18 & 17 & 9.04 & 30 & 15.96 & 56 & 11.67 & 86 & 17.92 \\
\hline High School Level & 71 & 24.32 & 57 & 19.52 & 51 & 27.13 & 46 & 24.47 & 122 & 25.42 & 103 & 21.46 \\
\hline $\begin{array}{ll}\text { High } & \text { School } \\
\text { Graduate } & \end{array}$ & 75 & 25.68 & 60 & 20.55 & 45 & 23.94 & 41 & 21.81 & 120 & 25.00 & 101 & 21.04 \\
\hline College Level & 35 & 11.99 & 34 & 11.64 & 31 & 16.49 & 19 & 10.11 & 66 & 13.75 & 53 & 11.04 \\
\hline College Graduate & 37 & 12.67 & 22 & 7.53 & 21 & 11.17 & 14 & 7.45 & 58 & 12.08 & 36 & 7.50 \\
\hline Short Term Course & 35 & 11.99 & 6 & 2.05 & 2 & 1.06 & 2 & 1.06 & 2 & 0.42 & 8 & 1.67 \\
\hline
\end{tabular}

Table 5. Couples' occupation

\begin{tabular}{|c|c|c|c|c|c|c|c|c|c|c|c|c|}
\hline \multirow[t]{3}{*}{ Occupation } & \multicolumn{4}{|l|}{$4 \mathrm{Ps}$} & \multicolumn{4}{|c|}{ Non-4Ps } & \multicolumn{4}{|c|}{ Total } \\
\hline & \multicolumn{2}{|c|}{ Wife } & \multicolumn{2}{|c|}{ Husband } & \multicolumn{2}{|c|}{ Wife } & \multicolumn{2}{|c|}{ Husband } & \multicolumn{2}{|c|}{ Wife } & \multicolumn{2}{|c|}{ Husband } \\
\hline & $\mathrm{F}$ & $\%$ & $\mathrm{~F}$ & $\%$ & $\mathrm{~F}$ & $\%$ & $\mathrm{~F}$ & $\%$ & $\mathrm{~F}$ & $\%$ & $\mathrm{~F}$ & $\%$ \\
\hline Unemployed & 251 & 85.96 & & & 147 & 78.19 & & & 398 & 82.92 & & \\
\hline Self-employed & & & 162 & 55.48 & & & 52 & 27.66 & & & 214 & 44.58 \\
\hline $\begin{array}{l}\text { Employed-daily } \\
\text { wage basis }\end{array}$ & 25 & 8.56 & 86 & 29.45 & 19 & 10.11 & 70 & 37.23 & 44 & 9.17 & 156 & 32.50 \\
\hline $\begin{array}{l}\text { Employed- } \\
\text { commission basis }\end{array}$ & 1 & 0.34 & 36 & 12.33 & 6 & 3.19 & 48 & 25.53 & 7 & 1.46 & 84 & 17.50 \\
\hline $\begin{array}{l}\text { Employed-monthly } \\
\text { wage basis }\end{array}$ & 8 & 2.74 & 5 & 1.71 & 9 & 4.79 & 17 & 9.04 & 17 & 3.54 & 22 & 4.58 \\
\hline $\begin{array}{l}\text { Employed- } \\
\text { honorarium basis }\end{array}$ & 7 & 2.40 & 3 & 1.03 & 7 & 3.72 & 1 & 0.53 & 14 & 2.92 & 4 & 0.83 \\
\hline
\end{tabular}


Table 6. Couples' religion

\begin{tabular}{|c|c|c|c|c|c|c|c|c|c|c|c|c|}
\hline \multirow{3}{*}{ Religion } & \multicolumn{4}{|l|}{ 4Ps } & \multicolumn{4}{|c|}{ Non-4Ps } & \multicolumn{4}{|c|}{ Total } \\
\hline & \multicolumn{2}{|c|}{ Wife } & \multicolumn{2}{|c|}{ Husband } & \multicolumn{2}{|c|}{ Wife } & \multicolumn{2}{|c|}{ Husband } & \multicolumn{2}{|c|}{ Wife } & \multicolumn{2}{|c|}{ Husband } \\
\hline & $\mathrm{F}$ & $\%$ & $\mathrm{~F}$ & $\%$ & $\mathrm{~F}$ & $\%$ & $\mathrm{~F}$ & $\%$ & $\mathrm{~F}$ & $\%$ & $\mathrm{~F}$ & $\%$ \\
\hline Catholics & 216 & 73.97 & 224 & 76.71 & 134 & 71.28 & 149 & 79.26 & 350 & 72.92 & 373 & 77.71 \\
\hline $\begin{array}{l}\text { Non- } \\
\text { Catholics }\end{array}$ & 76 & 26.03 & 68 & 23.29 & 54 & 28.72 & 39 & 20.74 & 130 & 27.08 & 107 & 22.29 \\
\hline
\end{tabular}

Table 7. Couples' Ethnicity

\begin{tabular}{|c|c|c|c|c|c|c|c|c|c|c|c|c|}
\hline \multirow[t]{3}{*}{ Ethnic Group } & \multicolumn{4}{|c|}{ 4Ps } & \multicolumn{4}{|c|}{ Non-4Ps } & \multicolumn{4}{|c|}{ Total } \\
\hline & \multicolumn{2}{|c|}{ Wife } & \multicolumn{2}{|c|}{ Husband } & \multicolumn{2}{|c|}{ Wife } & \multicolumn{2}{|c|}{ Husband } & \multicolumn{2}{|c|}{ Wife } & \multicolumn{2}{|c|}{ Husband } \\
\hline & $\mathrm{F}$ & $\%$ & $\mathrm{~F}$ & $\%$ & $\mathrm{~F}$ & $\%$ & $\mathrm{~F}$ & $\%$ & $\mathrm{~F}$ & $\%$ & $\mathrm{~F}$ & $\%$ \\
\hline Tagalog & 39 & 13.36 & 34 & 11.64 & 20 & 10.64 & 12 & 6.38 & 59 & 12.29 & 46 & 9.58 \\
\hline Ilokano & $\begin{array}{l}18 \\
6\end{array}$ & 63.70 & 191 & 65.41 & 106 & 56.38 & 122 & 64.89 & 292 & 60.83 & 313 & 65.21 \\
\hline Ibanag & 30 & 10.27 & 33 & 11.30 & 21 & 11.17 & 21 & 11.17 & 51 & 10.63 & 54 & 11.25 \\
\hline Itawes & 20 & 6.85 & 22 & 7.53 & 27 & 14.36 & 27 & 14.36 & 47 & 9.79 & 49 & 10.21 \\
\hline Igorots & 10 & 3.42 & 8 & 2.74 & 10 & 5.32 & 1 & 0.53 & 20 & 4.17 & 9 & 1.88 \\
\hline $\begin{array}{l}\text { Others } \\
\text { (Bugkalots, } \\
\text { Gaddangs) }\end{array}$ & 7 & 2.40 & 4 & 1.37 & 4 & 2.13 & 5 & 2.66 & 11 & 2.29 & 9 & 1.88 \\
\hline
\end{tabular}

Table 8. Number of Children in the Family

\begin{tabular}{|l|l|l|l|l|l|l|}
\hline \multirow{2}{*}{ Number of Children } & 4Ps & \multicolumn{2}{l|}{ Non-4Ps } & \multicolumn{2}{l|}{ Total } \\
\cline { 2 - 8 } & F & \% & F & \% & F & \% \\
\hline $1-2$ & 73 & 25.00 & 54 & 28.72 & 127 & 26.46 \\
\hline $3-4$ & 131 & 44.86 & 75 & 39.89 & 206 & 42.92 \\
\hline $5-6$ & 64 & 21.92 & 43 & 22.87 & 107 & 22.29 \\
\hline $7-8$ & 21 & 7.19 & 10 & 5.32 & 31 & 6.46 \\
\hline $9-12$ & 3 & 1.03 & 6 & 3.19 & 9 & 1.88 \\
\hline Total & 292 & 100.00 & 188 & 100.00 & 480 & 100.00 \\
\hline & \multicolumn{2}{|c|}{3.82} & \multicolumn{2}{|c|}{3.83} & \multicolumn{2}{c|}{3.82} \\
\hline
\end{tabular}

Table 9. Wives' age at marriage and menarche, number of pregnancies, Spacing Between Pregnancies

\begin{tabular}{|c|c|c|c|c|c|c|c|}
\hline \multirow{2}{*}{\multicolumn{2}{|c|}{ Wife's Reproductive Profile }} & \multicolumn{2}{|l|}{$4 \mathrm{Ps}$} & \multicolumn{2}{|c|}{ Non-4Ps } & \multicolumn{2}{|c|}{ Total } \\
\hline & & & & & & & \\
\hline \multirow{6}{*}{ wife's age at marriage } & 17 and below & 53 & 18.15 & 30 & 15.96 & 83 & 17.29 \\
\hline & $18-20$ & 123 & 42.12 & 80 & 42.55 & 203 & 42.29 \\
\hline & $21-23$ & 68 & 23.29 & 36 & 19.15 & 104 & 21.67 \\
\hline & $24-26$ & 29 & 9.93 & 20 & 10.64 & 49 & 10.21 \\
\hline & 17 and below & 53 & 18.15 & 30 & 15.96 & 83 & 17.29 \\
\hline & Mean & \multicolumn{2}{|c|}{20.54} & \multicolumn{2}{|c|}{20.88} & \multicolumn{2}{|c|}{20.68} \\
\hline \multirow[t]{4}{*}{ Age at Menarche } & Less than ten years old & 1 & 0.34 & & & 1 & 0.21 \\
\hline & $10-13$ years old & 139 & 47.60 & 107 & 56.91 & 246 & 51.25 \\
\hline & $14-16$ years old & 141 & 48.29 & 76 & 40.43 & 217 & 45.21 \\
\hline & 17 years old & 11 & 3.77 & 5 & 2.66 & 16 & 3.33 \\
\hline \multirow[t]{7}{*}{ Number of Pregnancies } & $1-2$ & 65 & 22.26 & 50 & 26.60 & 115 & 23.96 \\
\hline & $3-4$ & 130 & 44.52 & 72 & 38.30 & 202 & 42.08 \\
\hline & $5-6$ & 68 & 23.29 & 46 & 24.47 & 114 & 23.75 \\
\hline & $7-8$ & 23 & 7.88 & 12 & 6.38 & 35 & 7.29 \\
\hline & $9-10$ & 6 & 2.05 & 6 & 3.19 & 12 & 2.50 \\
\hline & $11-13$ & & & 2 & 1.06 & 2 & 0.42 \\
\hline & Mean & \multicolumn{2}{|l|}{3.99} & \multicolumn{2}{|l|}{4.07} & \multicolumn{2}{|l|}{4.02} \\
\hline \multirow[t]{6}{*}{ Gaps Between Pregnancies } & $<1$ & 13 & 4.45 & 14 & 7.45 & 27 & 5.63 \\
\hline & 1 & 106 & 36.30 & 64 & 34.04 & 170 & 35.42 \\
\hline & 2 & 104 & 35.62 & 75 & 39.89 & 179 & 37.29 \\
\hline & 3 & 32 & 10.96 & 23 & 12.23 & 55 & 11.46 \\
\hline & 4 & 18 & 6.16 & 5 & 2.66 & 23 & 4.79 \\
\hline & $>5$ & 19 & 6.49 & 6 & 3.19 & 25 & 5.23 \\
\hline
\end{tabular}


Table 10. Wives' child delivery profile

\begin{tabular}{|l|l|l|}
\hline Delivery Profile & Frequency & Percentage (\%) \\
\hline $\begin{array}{l}\text { *with the complete number of deliveries based on the number of } \\
\text { pregnancies }\end{array}$ & 423 & 88.13 \\
\hline With 1 miscarriages/ spontaneous abortions & 46 & 9.58 \\
\hline With 2 miscarriages/ spontaneous abortions & 9 & 1.88 \\
\hline With 3 miscarriages/ spontaneous abortions & 1 & 0.21 \\
\hline With 11 miscarriages/ spontaneous abortions & 1 & 0.21 \\
\hline TOTAL & 480 & 100.00 \\
\hline
\end{tabular}

Table 13. Distribution of wives according to their full term delivery profile

\begin{tabular}{|l|l|l|}
\hline Delivery Profile & Frequency & Percentage (\%) \\
\hline $\begin{array}{l}* \text { with the complete number of full-term deliveries based on the } \\
\text { number of deliveries }\end{array}$ & 451 & 93.96 \\
\hline With one non-full term delivery & 22 & 4.58 \\
\hline With 2non-full term deliveries & 7 & 1.46 \\
\hline TOTAL & 480 & 100.00 \\
\hline
\end{tabular}

Table 14. Couple's level of knowledge on family planning methods

\begin{tabular}{|c|c|c|c|c|c|c|}
\hline \multirow[t]{2}{*}{ Family Planning Methods } & \multicolumn{2}{|l|}{ 4Ps } & \multicolumn{2}{|c|}{ Non-4Ps } & \multicolumn{2}{|c|}{ Overall } \\
\hline & Mean & QD & Mean & QD & Mean & QD \\
\hline \multicolumn{7}{|l|}{ Scientific Modern NFP Methods } \\
\hline Basal Body Temp & 2.25 & Moderate & 2.09 & Moderate & 2.19 & Moderate \\
\hline Symptothermal & 2.22 & Moderate & 2.14 & Moderate & 2.19 & Moderate \\
\hline Lactational Ammenorrhea & 2.81 & Moderate & 2.71 & Moderate & 2.77 & Moderate \\
\hline $\begin{array}{l}\text { Billings Ovulation/Cervical } \\
\text { Mucus Method }\end{array}$ & 2.55 & Moderate & 2.40 & Moderate & 2.49 & Moderate \\
\hline Standard Days Method & 2.28 & Moderate & 2.11 & Moderate & 2.21 & Moderate \\
\hline Two-day method & 1.83 & Low & 1.83 & Low & 1.83 & Low \\
\hline Category Mean & 2.32 & Moderate & 2.21 & Moderate & 2.28 & Moderate \\
\hline \multicolumn{7}{|l|}{ Artificial Methods } \\
\hline Condom & 3.52 & High & 3.50 & High & 3.51 & High \\
\hline Depo Provera & 3.56 & High & 3.52 & High & 3.54 & High \\
\hline Intra-uterine Device(IUD) & 3.44 & High & 3.49 & High & 3.46 & High \\
\hline Pills & 3.64 & High & 3.64 & High & 3.64 & High \\
\hline Vasectomy & 3.03 & High & 2.94 & Moderate & 2.99 & Moderate \\
\hline Bilateral Tubal Ligation (BTL) & 3.41 & High & 3.36 & High & 3.39 & High \\
\hline Category Mean & 3.43 & High & 3.41 & High & 3.42 & High \\
\hline \multicolumn{7}{|l|}{ Traditional Method } \\
\hline Calendar method & 2.95 & Moderate & 2.78 & Moderate & 2.88 & Moderate \\
\hline Withdrawal & 3.44 & High & 3.42 & High & 3.43 & High \\
\hline Category Mean & 3.19 & High & 3.10 & High & 3.16 & High \\
\hline
\end{tabular}

Table 15. Users of family planning methods among counples

\begin{tabular}{|l|l|l|l|l|l|l|}
\hline \multirow{2}{*}{ FP methods' utilization status } & 4Ps & Non-4Ps & Total \\
\cline { 2 - 7 } & $\mathrm{F}$ & $(\%)$ & $\mathrm{F}$ & $(\%)$ & F & $(\%)$ \\
\hline Users & 276 & 94.52 & 181 & 96.28 & 457 & 95.21 \\
\hline Non-Users & 16 & 5.48 & 7 & 3.72 & 23 & 4.79 \\
\hline Total & 292 & 100.00 & 188 & 100.00 & 480 & 100.00 \\
\hline
\end{tabular}


Table 16. Family planning methods used by couples

\begin{tabular}{|c|c|c|c|c|c|c|c|c|}
\hline \multicolumn{2}{|c|}{ Family Planning Methods } & \multicolumn{2}{|l|}{ 4Ps } & \multicolumn{2}{|c|}{ Non-4Ps } & \multicolumn{2}{|c|}{ Total } & \multirow{3}{*}{$\begin{array}{l}\text { Rank } \\
8\end{array}$} \\
\hline & & $\mathrm{F}$ & $\%$ & $\mathrm{~F}$ & $\%$ & $\mathrm{~F}$ & $\%$ & \\
\hline \multirow{6}{*}{$\begin{array}{l}\text { Scientific NFP } \\
\text { Methods }\end{array}$} & Basal Body Temp & 8 & 2.74 & 1 & 0.53 & 9 & 1.88 & \\
\hline & Symptothermal & 3 & 1.03 & 4 & 2.13 & 7 & 1.46 & 11.5 \\
\hline & LactationalAmmenorrhea & 30 & 10.27 & 13 & 6.91 & 43 & 8.96 & 6.5 \\
\hline & Billings Ovulation & 6 & 2.05 & 2 & 1.06 & 8 & 1.67 & 10 \\
\hline & Standard Days Method & 4 & 1.37 & 0 & 0.00 & 4 & 0.83 & 13 \\
\hline & Two-day method & 1 & 0.34 & 1 & 0.53 & 2 & 0.42 & 14 \\
\hline \multirow{6}{*}{$\begin{array}{l}\text { Artificial } \\
\text { Methods }\end{array}$} & Condom & 25 & 8.56 & 9 & 4.79 & 34 & 7.08 & 9 \\
\hline & Depo Provera & 122 & 41.78 & 52 & 27.66 & 174 & 36.25 & 2 \\
\hline & Intra-uterine Device(IUD) & 28 & 9.59 & 34 & 18.09 & 52 & 10.83 & 5 \\
\hline & Pills & 204 & 69.86 & 139 & 73.94 & 347 & 72.29 & 1 \\
\hline & Vasectomy & 0 & 0.00 & 2 & 1.06 & 2 & 0.42 & 11.5 \\
\hline & Bilateral Tubal Ligation & 47 & 16.10 & 21 & 11.17 & 68 & 14.17 & 4 \\
\hline \multirow{2}{*}{$\begin{array}{l}\text { Traditional } \\
\text { Methods }\end{array}$} & Calendar method & 27 & 9.25 & 16 & 8.51 & 43 & 8.96 & 6.5 \\
\hline & Withdrawal & 66 & 22.60 & 45 & 23.94 & 121 & 25.21 & 3 \\
\hline
\end{tabular}

Table 17 Number of FP methods tried by couples

\begin{tabular}{|c|c|c|c|c|c|c|}
\hline \multirow{2}{*}{$\begin{array}{l}\text { Number of FP methods } \\
\text { tried }\end{array}$} & \multicolumn{2}{|c|}{ Scientific (Modern NFP) } & \multicolumn{2}{|c|}{ Artificial FP } & \multicolumn{2}{|c|}{ Traditional (NFP) } \\
\hline & $\mathrm{F}$ & $(\%)$ & $\mathrm{F}$ & $(\%)$ & $\mathrm{F}$ & $(\%)$ \\
\hline 0 & 424 & 88.33 & 52 & 10.83 & 344 & 71.67 \\
\hline 1 & 47 & 9.79 & 224 & 46.67 & 108 & 22.50 \\
\hline 2 & 5 & 1.04 & 163 & 33.96 & 28 & 5.83 \\
\hline 3 & 2 & 0.42 & 37 & 7.71 & & \\
\hline 4 & 1 & 0.21 & 4 & 0.83 & & \\
\hline \multicolumn{7}{|l|}{5} \\
\hline 6 & 1 & 0.21 & & & & \\
\hline \multicolumn{7}{|l|}{7} \\
\hline 8 & 1 & 0.21 & & & & \\
\hline Total & 480 & 100.00 & 480 & 100.00 & 480 & 100.00 \\
\hline
\end{tabular}

Table 18. t-test analysis on the knowledge of 4Ps and non-4Ps on the Scientific family planning methods

\begin{tabular}{|c|c|c|c|c|}
\hline \multicolumn{2}{|c|}{ Family Planning Methods } & \multirow{2}{*}{$\begin{array}{l}\text { Computed Value } \\
2.01\end{array}$} & \multirow{2}{*}{$\begin{array}{l}\text { Probability Value } \\
0.045\end{array}$} & \multirow{2}{*}{$\begin{array}{l}\text { Interpretation } \\
\text { Significant }\end{array}$} \\
\hline Scientific Methods & Basal Body Temperature & & & \\
\hline & Symptothermal & 1.00 & 0.32 & Not significant \\
\hline & LactationalvAmmenorrhea & 1.27 & 0.21 & Not significant \\
\hline & $\begin{array}{l}\text { Billings Ovulation/ } \\
\text { Cervical Mucus }\end{array}$ & 1.75 & 0.08 & Not significant \\
\hline & Standard Days Method & 2.09 & 0.04 & Significant \\
\hline & Two-day method & 0.03 & 0.97 & Not significant \\
\hline \multirow[t]{6}{*}{ Artificial Methods } & Condom & 0.34 & 0.73 & Not Significant \\
\hline & Depo Provera & 0.70 & 0.48 & Not Significant \\
\hline & Intra-uterine Device(IUD) & -0.80 & 0.42 & Not Significant \\
\hline & Pills & -0.11 & 0.92 & Not Significant \\
\hline & Vasectomy & 1.16 & 0.25 & Not Significant \\
\hline & Bilateral Tubal Ligation (BTL) & 0.87 & 0.39 & Not Significant \\
\hline \multirow[t]{2}{*}{ Traditional Methods } & Calendar method & 2.10 & 0.04 & Significant \\
\hline & Withdrawal & 0.26 & 0.79 & Not Significant \\
\hline
\end{tabular}


Table 19. Chi-Square analysis of the utilization of the family planning methods by the 4Ps and non-4Ps couples

\begin{tabular}{|l|l|l|l|l|}
\hline \multicolumn{2}{|l}{ Family Planning Methods } & $\begin{array}{l}\text { Computed } \\
\text { Value }\end{array}$ & $\begin{array}{l}\text { Probability } \\
\text { Value }\end{array}$ & $\begin{array}{l}\text { Decision } \\
\alpha=0.05\end{array}$ \\
\hline Scientific Methods & Basal Body Temp & 1.95 & 0.16 & Not significant \\
\hline & Symptothermal & 0.35 & 0.55 & Not significant \\
\hline & LactationalAmmenorrhea & 1.20 & 0.27 & Not significant \\
\hline & Billings Ovulation & 0.21 & 0.64 & Not significant \\
\hline & Standard Days Method & 1.20 & 0.27 & Not significant \\
\hline & Two-day method & 0.00 & 1.00 & Not significant \\
\hline Artificial Methods & Condom & 1.94 & 0.16 & Not significant \\
\hline & Depo Provera & 9.27 & 0.002 & significant \\
\hline & Intra-uterine evice(IUD) & 0.89 & 0.35 & Not significant \\
\hline & Pills & 0.29 & 0.59 & Not significant \\
\hline & Vasectomy & 1.05 & 0.31 & Not significant \\
\hline & Bilateral Tubal Ligation & 1.90 & 0.17 & Not significant \\
\hline Traditional Methods & Calendar & 0.01 & 0.91 & Not Significant \\
\hline & Withdrawal & 0.17 & 0.68 & Not Significant \\
\hline
\end{tabular}

\section{References}

Beal, S. (2014). 6 Fertility myths and misconceptions revealed. HUFFPOST. [Online] Available: https://www.huffingtonpost.com/stephanie-beall-md-phd/6-fertility-myths-and-misconceptionsrevealed_b_4536006.html (s)

Dar, L. (2011). Health dept advises couples to observe 3 to $5 \mathrm{yr}$ birth spacing. Baguio Midland Courier. [Online] Available: http://www.baguiomidlandcourier.com.ph/

Department of Health [n.d.] Is withdrawal a modern natural family planning method? [Online] Available: https://www.doh.gov.ph/node/1148.

Department of Health (n.d.). What is reproductive health? [Online] Available: https://www.doh.gov.ph/node/1372

Dungog-Cuizon, A. L., and Cuizon, C.B. (2016). The Pantawid Pamilyang Pilipino Program (4Ps)" A Philippines open government partnership (OGP) initiative. CNU Journal of Higher Education, 10 (2016), 46-58. [Online] Available: http://jhe.cnu.edu.ph/index.php/cnujhe/article/view/197/130

Nallari, R. \& Griffith, B. (2011). Understanding growth and poverty theory, policy, and empirics. The International Bank for Reconstruction and Development. The World Bank. Washington DC. [Online] Available: https://openknowledge.worldbank.org/bitstream/handle/10986/2281/600570PUB0REPL10Box358306B01PU BLIC1.pdf?sequence $=1$

National Statistics Office [Philippines] and ICF Macro (2009). Philippines National Demographic and Health Survey 2008: Key Findings. Calverton, Maryland, USA: NSO and ICF Macro.

Official Gazette (2019). Pantawid Pamilyang Pilipino Program. [Online] Available: https://www.officialgazette. gov.ph/programs/conditional-cash-transfer/

Philippines Population Review (2019). Ethnicity, religion, and language in the Philippines.World Population Review.

Rees M.(1995). The age of menarche. National Center for Biotechnology Information, U.S. National Library of Medicine (4):2-4.

Suyu, E. (2015). Cagayan Valley: The Ibanag. National Commission for Culture and Arts. [Online] Available: https://ncca.gov.ph/about-ncca

United Nations Population Division (n.d.). Contraceptive prevalence. [Online] Available: https://data.worldbank.org/indicator/SP.DYN.CONM.ZS?view=chart 